Every microsporangium contains a small percentage (about 0.1 per cent) of abnormal pollen grains. These are oval, and each apparently represents two normal grains. There is a single nucleus, and at the first mitosis there are about 18 chromosomes.

University College,

GEOFFREY K. BERRIF

Ibadan.

Dec. 15.

${ }^{2}$ Darlington, C. D., and Wylie, A. P., "Chromosome Atlas of Flowering Plants" (London, 1955)

\section{Relationship between Dictyocotyle and Calicotyle}

RECENTLY, the opinion has been expressed that the endoparasitic monogenetic trematode Dictyocotyle coeliaca is simply a coelomic form of the common cloacal parasite Calicotyle which has entered, through the abdominal pores, the body cavity of certain species of Raia ${ }^{1}$. The normal posterior adhesive organ ('opisthaptor') was thought to be lost, and its central boss to regenerate a 'pseudohaptor'. The evidence given in support of this supposed ontogenetic migration was : (1) the finding, in an abdominal canal, of a trematode which had lost its opisthaptor; (2) the recovery, from the cloaca, of six isolated opisthaptors each with a central perforation which matched the boss of the mutilated specimen.

In expressing the above opinion, Dawes and Griffiths appear to have ignored several differences between $D$. coeliaca and $C$. kroyeri $i^{2,3}$. To these previously recognized differences may be added the following. There is a characteristic difference in the shape and size of the egg capsule, as may be seen by comparing the illustrations by Hunter and $K_{\text {Kille }}^{2}$ of $D$. coeliaca and by Dawes ${ }^{4}$ and by Euzet ${ }^{5}$ of $C$. kroyeri. Thave confirmed this difference by examining hundreds of capsules from each of the two parasites, and the difference in the egg capsules is accompanied by a corresponding difference in the size and shape of the respective ootypes. Furthermore, there is a difference in the relationship of the length of the sclerotized penis to the length of the body

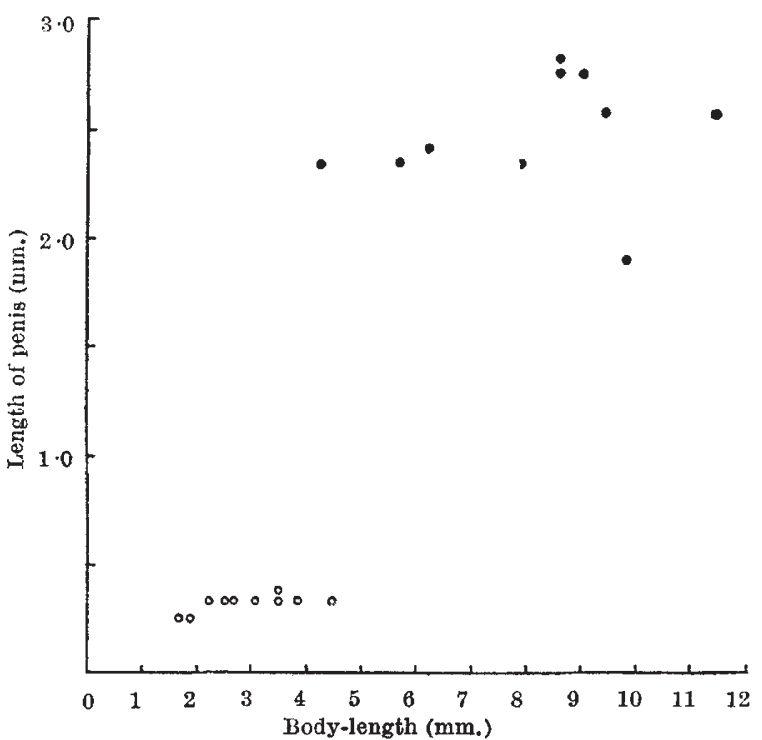
Fig. 1. Relative lengths of penis and body-proper (excluding
posterior adhesive apparatus) in some monogenean parasites of Raia species : 0 , from colom; O, from cloaca proper in each of the two parasites as illustrated in Fig. 1, which is based on measurements taken from a random sample of 10 cloacal and 10 coelomic parasites from Plymouth rays ${ }^{3}$.

It is conceivable that some of the differences between the cloacal and colomic parasites, for example, the development of diverticula from the intestinal cæca, and the lobing of the proximal region of the ovary, could possibly result from normal growth. But some other differences, for example, the re-orientation of the vaginæ and of the intestinal cæca, and the change in shape of the ootype, would involve a drastic re-organization of the body. Such a re-organization is not suggested by what is in fact known about the ontogenetic development of D. coeliaca. Hunter and Kille ${ }^{2}$ have observed three young specimens $(1 \cdot 4,2 \cdot 2$ and $2.5 \mathrm{~mm}$. long respectively) in which the course of the intestinal cæca was as in the adult. Moreover, the posterior adhesive organ in these three very small specimens (compare the measurements with those given in Fig. 1), together with that in a fourth specimen only 0.57 $\mathrm{mm}$. long, was of the $D$. coeliaca form, that is, having numerous shallow loculi.

C. kroyeri from the cloaca is known to produce egg capsules that yield larvæ ${ }^{5}$. Why then should the animal, after producing such capsules, indulge in something approaching a metamorphosis, migrate to a new ecological niche, and there produce further egg capsules? Such a pattern of life-cycle would be, so far as I am aware, unique in the animal kingdom. Phylogenetically, the adoption by $D$. coeliaca of a habitat completely within the host could well have been by way of the abdominal canals from the cloaca to the coelom-indeed this seems probable, and D. coeliaca and $C$. kroyeri are obviously closely related. Eventually it may be shown that the two species are better regarded as belonging to the same genus, but in the meantime there are no grounds for dissenting from Brinkmann's acceptance of two separate genera, a conclusion based on a thorough comparative review of six species of Calicotyle ${ }^{6}$ and of Dictyocotyle coeliaca ${ }^{7}$.

There is nothing in the recent observations by Dawes and Griffiths that would be inconsistent with their having found parts of damaged but otherwise normal specimens of Calicotyle kroyeri in the eloacas and abdominal canal of Plymouth hosts which they identified as Raia radiata. (The species of Raia at Plymouth have been studied in detail8, , but $R$. radiata had never been recorded previously.)

\section{J. LLEWELLIYN}

Department of Zoology and Comparative Physiology, The University, Edgbaston, Birmingham 15. Dec. 9.

1 Dawes, B., and Griffths, I., Nature, 182, 1033 (1958).

${ }^{2}$ Hunter, G. C., and Kille, R. A., J. Helminth., 24, 15 (1950).

${ }^{3}$ Llewellyn, J., and Green, J. E., J. Mar. Biol. Assoc. O.K., 36, 77

(1957). “"The Trematoda of British Fishes" (The Ray Society,
"Dawes, B., "The London, 1947)

- Euzet, L., Ann. Parasit. Hum. et Comp., 32, 197 (1957).

'Brinkmann, A., Univ. Bergen Arb. naturv. R., No. 1 (1939-40).

' Brinkmann, A., Univ. Bergen Arb. naturv. R., No. 1 (1952).

s Marine Biological Association, "Plymouth Marine Fauna, 1957".

- Steven, G. A., J. Mar. Biol. Assoc. V.K., 18, 1 (1932).

IN giving our opinion that 'Dictyocotyle' is simply a cœlomic form of Calicotyle we were well aware of some apparent structural differences between the two forms. Indeed, some of the supposedly distinctive characters had been detailed ${ }^{\mathbf{1}}{ }^{2}$. Perhaps the most obvious difference is one of size; Calicotyle rarely 